\title{
Comparison of Three Protocols: Dietary Therapy and Physical Activity, Acupuncture, or Laser Acupuncture in Management of Obese Females
}

\author{
Nayera E Hassan ${ }^{1}$, Sahar A El-Masry ${ }^{1 *}$, Salwa M Elshebini ${ }^{2}$, Muhamed Al-Tohamy ${ }^{1}$, Nihad H Ahmed ${ }^{2}$, Enas Abdel \\ Rasheed $^{3}$, Gamila SM El-Saeed ${ }^{4}$, Nagwa M Hassan ${ }^{5}$, Emad N Zikri $^{6}$, Mohamed S El Hussieny ${ }^{1}$ \\ ${ }^{1}$ Biological Anthropology Department, National Research Centre, Giza, Egypt; ${ }^{2}$ Nutrition and Food Science Department, \\ National Research Centre, Giza, Egypt; ${ }^{3}$ Clinical Pathology Department, National Research Centre, Cairo, Egypt; ${ }^{4}$ Medical \\ Biochemistry, National Research Centre, Cairo, Egypt; ${ }^{5}$ Head of Laser and Acupuncture Field, National Research Centre, \\ Cairo, Egypt; ${ }^{6}$ Complementary and Alternative Medicine Department, National Research Centre, Cairo, Egypt
}

\author{
Citation: Hassan NE, El-Masry SA, Elshebin \\ $\mathrm{SM}, \mathrm{Al}$-Tohamy M, Ahmed NH, Rasheed EA, El- \\ Saeed GSM, Hassan NM, Zikri EN, El Hussieny \\ MS. Comparison of Three Protocols: Dietary \\ Therapy and Physical Activity, Acupuncture, or \\ Laser Acupuncture in Management of Obese \\ Females. OA Maced J Med Sci. 2014 Jun 15; \\ 2(2):191-197. \\ http://dx.doi.org/10.3889/oamims.2014.030 \\ Key words: Obesity; visceral fat; Dietary \\ Measures and physical activity; acupuncture; \\ laser acupuncture. \\ "Correspondence: Prof. Sahar Abd El-Raufe \\ El-Masry., Biological Anthropology Dept., \\ National Research Centre, El-Bohooth St, \\ Dokk, Giza, Cairo 12622, Egypt. Phone \\ Received: 10-Feb-2014; Revised: 16-Ma \\ 2014; Accepted: 18-Mar-2014; Online first: \\ 16-Apr-2014 \\ Copyright: ( $\odot 2014$ Hassan et al. This is an \\ open-access article distributed under the terms \\ of the Creative Commons Attribution License, \\ which permits unrestricted use, distribution, \\ and reproduction in any medium, provided the \\ original author and source are credited. \\ Competing Interests: The authors have \\ declared that no competing interests exist.
}

\begin{abstract}
AIM: The aim of this study was to compare efficiency of three types of obesity management protocols: dietary measures and physical activity; acupuncture or laser acupuncture with healthy diet among obese females.

SUBJECTS AND METHODS: Randomized longitudinal prospective study, carried out on 76 adult females. Blood pressure, anthropometric, ultrasonographic and biochemical assessments were done.

RESULTS: Females undergo nutritional intervention showed highly significant improvement in the anthropometric measurements, visceral fat at umbilicus by US and diastolic blood pressure (decreased), and insignificant differences in fasting blood sugar and lipid profile. Female undergo acupuncture intervention showed highly significant improvement in visceral fat by US, lipid profile (decreased triglycerides, total cholesterol and LDL, and increased HDL), and decreased fasting blood sugar, and insignificant differences in the anthropometric measurements. Those undergo laser intervention showed highly significant improvement in all anthropometric measurements under study, visceral fat at umbilicus by US, blood pressure and some parameters of lipid profile (decreased total cholesterol and LDL).
\end{abstract}

CONCLUSIONS: Nutritional intervention alone could be used to reduce weight if the lipid profile within normal range, but if it is impaired, acupuncture should be used beside. To strength the reduction in body anthropometry, laser intervention was recommended beside the nutritional intervention.

\section{Introduction}

Obesity is a pervasive disease. In 2008, 1.5 billion adults worldwide were overweight and approximately 500 million adults were obese, and in 2010 nearly 43 million children younger than 5 years were overweight [1]. Egypt Demographic and Health Survey EDHS [2] stated that the proportions classified as obese increased directly with age, from a level of 10 percent among women aged 15-19 to 65 percent or more among women in the 45-59 age groups. Urban women were more likely to be obese than rural women, and the percentage classified as obese ranged from 25 percent in rural Upper Egypt to 49 percent in the urban Lower Egypt. Women in the highest wealth quintile were almost twice as likely as women in the lowest quintile to be obese.

Obesity must be considered as a disease in its own right. It is also a risk factor for other diseases, and frequently associated metabolic disorders [3].

Body mass index (BMI) and waist circumference (WC) are the indices commonly used for detecting obesity. They reflect total body weight and central distribution of fat. People with BMI $\geq 25$ are usually associated with high WC, but those with high WC are not necessarily having high BMI (overweight or obese). However, the risk for central obesity in 
those with normal or high BMI is increasing. For them, it is also necessary to reduce weight especially the fat in abdominal region. Fat is stored in the human body in the following sequence: intraperitoneal, abdominal subcutaneous, and subcutaneous in periphery [4]. Excess fat located in the intra-abdominal region (visceral fat) is associated with a greater disease risk than fat located in other areas [5].

The global increase in the prevalence of obesity has led to an increased need for measurement tools for research, management and treatment of the obese person especially with visceral obesity. The physical size limitations imposed by obesity, all pose tremendous challenges to the assessment of an obese person [6].

This management is necessary, since it can produce, in addition to weight reduction, an improvement in associated parameters, such as cardiovascular risk factors, metabolic disorders and the functional \& psychological status (i.e. guaranteeing better quality of life) [7].

There is little published research regarding which tools can be used with confidence. This research is designed to provide researchers and clinicians with a guide to the current and emerging management tools specifically associated with visceral obesity research and practice.

The aim of this work was to compare three types of treatment protocols to determine the efficiency of dietary therapy and physical activity, acupuncture or laser acupuncture with healthy diet in clinical management of obese females.

\section{Subjects and Methods}

This was a randomized longitudinal prospective study carried out from October 2011 to December 2012. It included obese females with a body mass index (BMI) greater than or equal to 30 $\mathrm{kg} / \mathrm{m}^{2}$ from the employee of the "National research Centre". Subjects were excluded if they presented with a contra-indication to effort, a major orthopedic problem, severe psychiatric disorders, a personal history of heart disease and/or a recent myocardial infarction, subjects not consenting to the protocol and those who had not diligently followed eight consecutive weeks of any of the three protocols. Participants were informed about the purpose of the study and their permission in the form of written consent was obtained. The protocol was approved by the "Ethical Committee" of the "National Research Centre". The agreement reference number is 10/119.

In all, 157 obese females were recruited. Only 76 females were included in the study analysis because the remaining had not correctly completed the initial follow up programme (due to a lack of diligence, a health problem .......etc). Their ages ranged between 26 up to 55 years, with mean age
$44.8 \pm 8.8$ years. All the participant females underwent blood pressure, anthropometric, ultrasonographic and biochemical assessments. Then, they were classified into 3 groups to undergo 3 different management protocols: dietary modification plan with exercise programme; acupuncture therapy and healthy diet; and laser acupuncture therapy with healthy diet.

Blood pressure was measured with a standard mercury sphygmanometer after the subjects had rested at least for 10 minutes.

Anthropometric evaluation was performed. The height, weight, waist, hip and neck circumferences were measured following the recommendations of the International Biological Program [8]. The height was measured to the nearest $0.1 \mathrm{~cm}$ using a Holtain portable anthropometer, and the weight was determined to the nearest $0.01 \mathrm{~kg}$ using a Seca Scale Balance, with the subject wearing minimal clothing and no shoes. Waist circumference was measured at the level of the umbilicus with the subject standing and breathing normally, hip circumference at the level of the iliac crest, neck circumference (NC) in the midway of the neck ( between mid-cervical spine and mid-anterior neck), using non-stretchable plastic tape to the nearest 0.1 $\mathrm{cm}$. All circumferences were taken with the subjects standing upright, with the face directed forward and shoulders relaxed. The following adiposity indices were calculated: body mass index (BMI): as weight (in kilograms) divided by height (in meters squared); and waist/ Hip ratio $(\mathrm{cm} / \mathrm{cm})$.

Ultrasound (US) examination to each participants was done to evaluate visceral fat at the umbilicus (USVF) in cm. Intra-abdominal fat thickness measurement was obtained using the "Medison Sonoace X8" Ultrasonographic equipment. For the visceral fat, a $3.5 \mathrm{MHz}$ transducer was transversely positioned $1 \mathrm{~cm}$ above the umbilical scar on the abdominal midline, without exerting any pressure over the abdomen. The visceral fat thickness attempted corresponding to the measurement in centimetres between the internal surface of the abdominal rectus muscle and the posterior aortic wall in the abdominal midline, during expiration.

Biochemical assessment: Early morning forearm venous blood samples $(10 \mathrm{ml})$ were obtained from each female; before breakfast; for biochemical screening tests of plasma glucose and lipid profile; after 12-hours overnight fasting. Professional staff performed venipuncture. The blood samples were left to clot; sera were separated by centrifugation for 10 minutes at $5000 \mathrm{rpm}$ then stored at $-80{ }^{\circ} \mathrm{C}$ until assays. Fasting glucose level was measured using a quantitative enzymatic colorimetric commercial kit provided by STANBIO according to the glucose oxidase method. Serum concentrations of total cholesterol (TC), triglycerides (TG) and high-density lipoprotein-cholesterol (HDL-C) were measured using 
commercially available kits provided by STANBIO Laboratory Inc. (1261 North 18 Res. J. Medicine \& Med. Sci., 8(1): 16-22, 2013. Main Street Boerne Texas 78006 USA). LDL-C was calculated according to an equation developed by Friedewald et al [9] as follows:

LDL-C $=$ Total cholesterol - Triglycerides $/ 5+$ HDL-C.

In terms of the females who were evaluated at the start and at the end of the programme, they were classified into three groups as follow: 30 females who had received dietary modification plan and underwent an exercise programme; 21 females made acupuncture therapy in addition to the healthy diet; and 25 females who received laser acupuncture therapy in addition to healthy diet.

Dietary modification plan (30 females): It was done under the supervision of a dietary consultant, and was followed to assess the impact of a dietary behaviour modification intervention to reach the ideal weight for age and sex. Nutritional education and behaviour modification were performed first. Then, performing adequate exercise (in form of walking for at least $150 \mathrm{~min} /$ week; each not less than $30 \mathrm{~min}$ ) and eating a healthy low caloric diet through participation evaluation, designing the program and patient education, specific programs for each age and sex group; and daily classes for health. Only 30 of them, who followed and completed the program, were included in the study.

The Prescribed Low Calorie Diet: The interview-based food survey was performed for all subjects by dieticians to specify previous food habits and possible anomalies in dietary behaviour. The prescribed low calorie diet was balanced, with $15 \%$ as protein, 30 to $35 \%$ as fat and 50 to $55 \%$ as carbohydrate, on average, in order to provide about 1000 calories daily for two months for whole participants in this study.

Three different low caloric diets were designed to be followed by the females; each was followed for about 3 months. The main daily food items that were prescribed were: boiled egg, low fat milk and dairy products, broad bean dip (Foul medams), steamed and fresh vegetables, fruits, whole grains product, low fat meat, chicken and fish which were either boiled or roasted. Green tea, coffee, cinnamon and natural fresh fruit were recommended as beverages. All sugar sweets and carbonate beverages were prohibited.

It was checked that food was eaten as three daily meals and emphasized the need to have a substantial breakfast. They underwent an identical dietary monitoring programme, with an initial consultation, a check-up in the middle of the programme and another during the final sessions by a dietician who was blinded to the type of the programme that the subject had been following.

Exercise Programme: as performing adequate exercise (in form of walking for at least $150 \mathrm{~min} / \mathrm{week}$ each not less than $30 \mathrm{~min}$ ) with light aerobic exercises for 5-10 min daily.

Acupuncture: 21 female received 12 body and auricular acupuncture sessions (once/week) using filiform disposable acupuncture needles with electrical stimulation. The acupuncture points were selected according to the theory of traditional Chinese medicine and the guidelines of WHO [10]. The total number of the points selected for obesity was 27 points: 3 auricular and 24 body acupuncture points each session.

Laser Acupuncture: 25 female received 12 laser sessions (once/week) using semiconductor diode laser (soft laser) wave length $808 \mathrm{~nm}$, power output $99 \mathrm{mw}$,and operation mode $\mathrm{CW}$ at the same points selected for group1. Laser apparatus used was SL-202 Gallium-Aluminium-Arsenide Laser (GaAIAs). Laser beam was directed to each acupuncture point for 30 seconds. Laser dose was calculated according to World Association of Laser Therapy (WALT) [11].

Statistical Analysis: Data were analyzed using the SPSS computer program, version 16.0. Means and standard deviation (SD) of all studied parameters were calculated separately. Paired dependant t-tests were performed to compare between the anthropometric measurements, blood pressure and biochemical assessment before and after intervention. Multivariate ANOVA test was used to compare between the three types of intervention before and after their use. $P$ value of 0.05 was considered significant.

\section{Results}

The female group who undergo nutritional intervention showed highly significant improvement in the anthropometric measurements (decrease in body weight, BMI, WC and Hip C), visceral fat at umbilicus by US and diastolic blood pressure (decreased). However, after nutritional intervention; there were insignificant differences in systolic blood pressure, fasting blood sugar and lipid profile (Tables 1,2).

Table 1: Comparison between the anthropometry among the nutritional diet female group before and after intervention using paired t-test.

\begin{tabular}{lrrrrrr}
\hline & \multicolumn{7}{c}{$\begin{array}{c}\text { Before } \\
\mathrm{N}=30\end{array}$} & \multicolumn{5}{c}{$\begin{array}{c}\text { After } \\
\mathrm{N}=30\end{array}$} & \multicolumn{1}{c}{$\mathrm{t}$} & $\mathrm{P}$ \\
& \multicolumn{1}{c}{ Mean } & \multicolumn{1}{c}{$\pm \mathrm{SD}$} & \multicolumn{1}{c}{ Mean } & \multicolumn{1}{c}{ SD } & & \\
\hline Weight $(\mathrm{Kg})$ & 86.61 & 14.44 & 80.94 & 15.99 & 6.26 & 0.000 \\
BMl $\left(\mathrm{Kg} / \mathrm{m}^{2}\right)$ & 34.44 & 6.37 & 32.54 & 6.79 & 4.70 & 0.000 \\
Waist C $(\mathrm{cm})$ & 97.77 & 8.64 & 93.85 & 12.80 & 4.07 & 0.000 \\
Hip C $(\mathrm{cm})$ & 116.90 & 9.50 & 110.92 & 10.10 & 4.74 & 0.000 \\
Waist/Hip ratio $(\mathrm{cm} / \mathrm{cm})$ & 0.84 & 0.05 & 0.84 & 0.06 & -0.04 & 0.967 \\
Neck C (cm) & 37.47 & 3.08 & 37.19 & 3.20 & 1.19 & 0.244 \\
Visceral Fat by US at & 5.52 & 1.44 & 4.82 & 2.03 & 2.24 & 0.033 \\
umbilicus & & & & & & \\
\hline
\end{tabular}

The female group who undergo acupuncture intervention showed highly significant improvement in visceral fat by US (decreased), lipid profile (decreased triglycerides, total cholesterol and LDL, and increased $\mathrm{HDL}$ ), and decreased fasting blood sugar. 
Table 2: Comparison between blood pressure and lipid profile among the nutritional diet female group before and after intervention using paired t-test.

\begin{tabular}{|c|c|c|c|c|c|c|}
\hline & \multicolumn{2}{|c|}{$\begin{array}{c}\text { Before } \\
\mathrm{N}=30\end{array}$} & \multicolumn{2}{|c|}{$\begin{array}{l}\text { After } \\
\mathrm{N}=30\end{array}$} & \multirow[t]{2}{*}{$t$} & \multirow[t]{2}{*}{$\mathrm{P}$} \\
\hline & Mean & $\pm \mathrm{SD}$ & Mean & $+\mathrm{SD}$ & & \\
\hline SBP & 120.00 & 25.19 & 115.00 & 17.13 & 0.89 & 0.838 \\
\hline DBP & 80.00 & 16.29 & 81.88 & 8.14 & -2.38 & 0.034 \\
\hline Fasting Blood sugar & 100.93 & 27.51 & 96.47 & 30.93 & 0.50 & 0.625 \\
\hline Total Cholesterol & 209.00 & 50.41 & 228.60 & 29. & -1.82 & 0.079 \\
\hline Triglycerides & 130.87 & 46.34 & 151.13 & 63.55 & -1.45 & 0.157 \\
\hline $\mathrm{HDL}$ & 51.07 & 12.26 & 48.40 & 10.36 & 1.05 & 0.303 \\
\hline LDL & 132.20 & 46.00 & 150.07 & 35.98 & -1.05 & 0.111 \\
\hline
\end{tabular}

However, after acupuncture intervention; there were insignificant differences in the anthropometric measurements except NC (Tables 3, 4).

Table 3: Comparison between the anthropometry among the acupuncture female group before and after intervention using paired t-test.

\begin{tabular}{|c|c|c|c|c|c|c|}
\hline & \multicolumn{2}{|c|}{$\begin{array}{l}\text { Before } \\
\mathrm{N}=21\end{array}$} & \multicolumn{2}{|c|}{$\begin{array}{l}\text { After } \\
\mathrm{N}=21\end{array}$} & \multirow[b]{2}{*}{$t$} & \multirow{2}{*}{$\mathrm{P}$} \\
\hline & Mean & $+\mathrm{SD}$ & Mean & $+\mathrm{SD}$ & & \\
\hline Weight (Kg) & 91.20 & 12.96 & 94.70 & 19.68 & -1.30 & 0.209 \\
\hline $\mathrm{BMI}\left(\mathrm{Kg} / \mathrm{m}^{2}\right)$ & 36.40 & 3.65 & 35.77 & 5.84 & 1.16 & 0.261 \\
\hline Waist C (cm) & 95.00 & 5.49 & 101.00 & 16.16 & -2.57 & 0.018 \\
\hline Hip C (cm) & 126.67 & 7.59 & 125.00 & 14.71 & 0.75 & 0.464 \\
\hline $\begin{array}{l}\text { Waist/Hip ratio } \\
(\mathrm{cm} / \mathrm{cm})\end{array}$ & 0.75 & 0.02 & 0.80 & 0.04 & -5.27 & 0.000 \\
\hline Neck C $(\mathrm{cm})$ & 40.00 & 5.22 & 37.67 & 4.29 & 3.97 & 0.001 \\
\hline $\begin{array}{l}\text { Visceral Fat by US at } \\
\text { umbilicus }\end{array}$ & 4.90 & 1.79 & 4.00 & 2.18 & 3.12 & 0.005 \\
\hline
\end{tabular}

The female group who undergo laser acupuncture intervention showed highly significant improvement in all the anthropometric measurements under study (decrease in body weight, BMI, WC, hip C and WHR) except NC, visceral fat at umbilicus by US (decreased), blood pressure (both systolic and diastolic) and some parameters of lipid profile (decreased total cholesterol and LDL) (Tables 5, 6).

Table 4: Comparison between blood pressure and lipid profile among the acupuncture female group before and after intervention using paired t-test.

\begin{tabular}{|c|c|c|c|c|c|c|}
\hline & \multicolumn{2}{|c|}{$\begin{array}{c}\text { Before } \\
\mathrm{N}=21\end{array}$} & \multicolumn{2}{|c|}{$\begin{array}{l}\text { After } \\
\mathrm{N}=21\end{array}$} & \multirow[t]{2}{*}{$t$} & \multirow[t]{2}{*}{$P$} \\
\hline & Mean & $\pm \mathrm{SD}$ & Mean & ${ }_{ \pm} \mathrm{SD}$ & & \\
\hline SBP & 145.00 & 4.18 & 145.00 & 5.19 & 0.00 & 1.000 \\
\hline DBP & 100.00 & 8.37 & 105.00 & 5.19 & & \\
\hline Fasting Blood sugar & 110.00 & 12.32 & 86.00 & 12.15 & 37.95 & 0.000 \\
\hline Total Cholesterol & 233.33 & 7.95 & 208.67 & 31.44 & 4.73 & 0.000 \\
\hline Triglycerides & 169.33 & 21.66 & 142.00 & 27.95 & 8.34 & 0.000 \\
\hline $\mathrm{HDL}$ & 43.67 & 4.76 & 58.00 & 2.90 & -13.40 & 0.000 \\
\hline LDL & 154.00 & 4.66 & 141.33 & 13.76 & 6.30 & 0.000 \\
\hline
\end{tabular}

Comparisons between groups before and after intervention

Before intervention, the females who were selected to laser acupuncture intervention had highly significant highest values of body anthropometry (BMI, waist and hip circumferences, waist/hip ratio), visceral fat by US and some parameters of lipid profile (triglycerides, total cholesterol and HDL). While females who were selected to acupuncture intervention had highly significant highest values of neck circumference, systolic and diastolic blood pressure (Tables 7, 8).
Table 5: Comparison between the anthropometry among the laser acupuncture female group before and after intervention using paired t-test.

\begin{tabular}{lrrrrrr} 
& \multicolumn{2}{c}{$\begin{array}{c}\text { Before } \\
\mathrm{N}=25\end{array}$} & \multicolumn{2}{c}{$\begin{array}{c}\text { After } \\
\mathrm{N}=25\end{array}$} & \multirow{2}{*}{$\mathrm{P}$} \\
\cline { 2 - 5 } & Mean & \multicolumn{1}{c}{$\pm \mathrm{SD}$} & \multicolumn{1}{c}{ Mean } & \multicolumn{1}{c}{$\pm \mathrm{SD}$} & & \\
\hline Weight $(\mathrm{Kg})$ & 96.18 & 18.63 & 89.34 & 18.04 & 6.81 & 0.000 \\
BMI $\left(\mathrm{Kg} / \mathrm{m}^{2}\right)$ & 41.38 & 10.53 & 38.54 & 9.60 & 5.01 & 0.000 \\
Waist C $(\mathrm{cm})$ & 111.40 & 20.26 & 99.90 & 13.50 & 6.42 & 0.000 \\
Hip C $(\mathrm{cm})$ & 127.60 & 19.02 & 121.30 & 19.00 & 1.97 & 0.000 \\
Waist/Hip ratio $(\mathrm{cm} / \mathrm{cm})$ & 0.87 & 0.06 & 0.83 & 0.05 & 9.08 & 0.000 \\
Neck C $(\mathrm{cm})$ & 39.60 & 1.38 & 40.10 & 2.10 & -0.85 & 0.406 \\
Visceral Fat by US at & 8.67 & 1.97 & 6.41 & 2.37 & 5.42 & 0.000 \\
umbilicus & & & & & & \\
\hline
\end{tabular}

However, the picture changed after intervention. The females who undergo acupuncture intervention became had highly significant highest values of body anthropometry (body weight and hip circumference), and still had highly significant highest values in blood pressure (both systolic and diastolic) (Tables 9, 10).These augment the effect of laser acupuncture intervention on body anthropometry.

Table 6: Comparison between blood pressure and lipid profile among the laser acupuncture female group before and after intervention using paired t-test.

\begin{tabular}{lrrrrrr}
\hline & \multicolumn{2}{c}{ Before } & \multicolumn{2}{c}{ After } & & \multirow{2}{*}{$\mathrm{N}=25$} \\
\cline { 2 - 5 } & \multicolumn{1}{c}{ Mean } & \multicolumn{1}{c}{ tSD } & \multicolumn{1}{c}{ Mean } & \multicolumn{1}{c}{ tSD } & & $\mathrm{P}$ \\
\hline SBP & 134.00 & 21.98 & 120.00 & 8.45 & 3.46 & 0.004 \\
DBP & 84.00 & 10.41 & 80.00 & 0.00 & 4.56 & 0.000 \\
Fasting Blood Sugar & 113.80 & 35.77 & 109.20 & 16.14 & 0.76 & 0.456 \\
Total Cholesterol & 238.80 & 32.17 & 206.00 & 24.49 & 2.99 & 0.006 \\
Triglycerides & 173.00 & 77.41 & 146.60 & 47.49 & 1.58 & 0.127 \\
HDL & 52.80 & 16.92 & 60.60 & 23.21 & -1.63 & 0.116 \\
LDL & 151.40 & 34.26 & 115.00 & 18.53 & 5.07 & 0.000 \\
\hline
\end{tabular}

\section{Discussion}

The National Heart, Lung, and Blood Institute (NHLBI) outlined the identification and evaluation of overweight and obesity in its 1998 clinical guidelines [12] (these are currently being revised). A careful assessment of weight status, the presence of co morbidities, as well as readiness for change is necessary to determine the appropriate treatment approach for an individual. An obese person with two or three co- morbidities would receive greater benefit from a more aggressive approach than an overweight person suffering no medical impact from excess body fat. Obesity treatment is one arena in which a onesize-fits-all approach does not ensure success [12].

Table 7: Comparison between the anthropometry among the 3 groups of females before intervention using ANOVA.

\begin{tabular}{|c|c|c|c|c|c|c|c|c|}
\hline & \multicolumn{2}{|c|}{$\begin{array}{l}\text { Nutritional group } \\
\qquad \mathrm{N}=30\end{array}$} & \multicolumn{2}{|c|}{$\begin{array}{l}\text { Acupuncture } \\
\text { group } \\
\mathrm{N}=21\end{array}$} & \multicolumn{2}{|c|}{$\begin{array}{l}\text { Laser group } \\
\mathrm{N}=25\end{array}$} & \multirow[t]{2}{*}{$\mathrm{F}$} & \multirow[t]{2}{*}{$P$} \\
\hline & Mean & ${ }_{ \pm} \mathrm{SD}$ & Mean & \pm SD & Mean & $+\mathrm{SD}$ & & \\
\hline $\begin{array}{l}\text { Age } \\
\text { (years) }\end{array}$ & 43.47 & 9.59 & 45.00 & 9.32 & 46.40 & 7.23 & 0.707 & 0.497 \\
\hline $\begin{array}{l}\text { Weight } \\
(\mathrm{Kg})\end{array}$ & 86.61 & 14.44 & 91.20 & 12.96 & 96.18 & 18.63 & 2.570 & 0.083 \\
\hline $\begin{array}{l}\text { Height } \\
(\mathrm{cm})\end{array}$ & 158.50 & 5.26 & 157.83 & 5.30 & 153.20 & 3.73 & 9.225 & 0.000 \\
\hline $\begin{array}{l}\text { BMI } \\
\left(\mathrm{Kg} / \mathrm{m}^{2}\right)\end{array}$ & 34.44 & 6.37 & 36.40 & 3.65 & 41.38 & 10.53 & 6.030 & 0.004 \\
\hline $\begin{array}{l}\text { Waist C } \\
(\mathrm{cm})\end{array}$ & 97.77 & 8.64 & 95.00 & 5.49 & 111.40 & 20.26 & 10.86 & 0.000 \\
\hline $\begin{array}{l}\text { Hip C } \\
\text { (cm) }\end{array}$ & 116.90 & 9.50 & 126.67 & 7.59 & 127.60 & 19.021 & 5.645 & 0.005 \\
\hline $\begin{array}{l}\text { Waist/Hip } \\
\text { ratio } \\
(\mathrm{cm} / \mathrm{cm})\end{array}$ & 0.84 & 0.05 & 0.75 & 0.02 & 0.87 & 0.06 & 33.23 & 0.000 \\
\hline $\begin{array}{l}\text { Neck C } \\
(\mathrm{cm})\end{array}$ & 37.47 & 3.08 & 40.00 & 5.22 & 39.60 & 1.38 & 4.18 & 0.019 \\
\hline $\begin{array}{l}\text { Visceral } \\
\text { Fat by } \\
\text { US at } \\
\text { umbilicus }\end{array}$ & 5.52 & 1.44 & 4.90 & 1.79 & 8.67 & 1.97 & 33.49 & 0.000 \\
\hline
\end{tabular}


The aim of the present study was to analyze and compare the changes in visceral obesity, anthropometric measurements, blood pressure as well as plasma lipid profile in response to three types of protocols to determine the efficiency of dietary measures and physical activity; acupuncture or laser acupuncture with healthy diet, in clinical management of obese females.

Table 8: Comparison between blood pressure and lipid profile among the 3 groups of females before intervention using ANOVA.

\begin{tabular}{|c|c|c|c|c|c|c|c|c|}
\hline & \multicolumn{2}{|c|}{$\begin{array}{c}\text { Nutritional group } \\
\mathrm{N}=30\end{array}$} & \multicolumn{2}{|c|}{$\begin{array}{l}\text { Acupuncture } \\
\text { group } \\
\mathrm{N}=21\end{array}$} & \multicolumn{2}{|c|}{$\begin{array}{l}\text { Laser group } \\
\quad \mathrm{N}=25\end{array}$} & \multirow[t]{2}{*}{$\mathrm{F}$} & \multirow[t]{2}{*}{ P } \\
\hline & Mean & $\pm \mathrm{SD}$ & Mean & $\pm \mathrm{SD}$ & Mean & $\pm \mathrm{SD}$ & & \\
\hline SBP & 120.00 & 25.19 & 145.00 & $\overline{4.18}$ & 134.00 & 21.98 & 9.56 & 0.000 \\
\hline DBP & 80.00 & 16.29 & 100.00 & 8.37 & 84.00 & 10.41 & 16.35 & 0.000 \\
\hline $\begin{array}{l}\text { Fasting } \\
\text { Blood sugar }\end{array}$ & 100.93 & 27.51 & 110.00 & 12.32 & 113.80 & 35.77 & 1.58 & 0.212 \\
\hline $\begin{array}{l}\text { Total } \\
\text { Cholesterol }\end{array}$ & 209.00 & 50.41 & 233.33 & 7.95 & 238.80 & 32.17 & 5.08 & 0.009 \\
\hline Triglycerides & 130.87 & 46.34 & 169.33 & 21.66 & 173.00 & 77.41 & 5.06 & 0.009 \\
\hline $\mathrm{HDL}$ & 51.07 & 12.26 & 43.67 & 4.76 & 52.80 & 16.92 & 3.31 & 0.042 \\
\hline LDL & 132.20 & 46.00 & 154.00 & 4.66 & 151.40 & 34.26 & 3.09 & 0.051 \\
\hline
\end{tabular}

The current results revealed that; although the three investigated tools had highly significant effect on visceral obesity, nutritional intervention has a good effect on the body anthropometry, but has minimal effect on lipid profile in females. While Laser intervention in females has a good effect on body anthropometry, visceral fat by US, and blood pressure, however, it affects only total cholesterol and LDL in lipid profile. On the other hand, Acupuncture intervention has a good effect on lipid profile and fasting blood sugar, and no effect on body anthropometry. These effects were augmented by comparing the 3 groups before and after intervention.

Table 9: Comparison between the anthropometry among the 3 groups of females after intervention using ANOVA.

\begin{tabular}{|c|c|c|c|c|c|c|c|c|}
\hline & \multicolumn{2}{|c|}{$\begin{array}{l}\text { Nutritional group } \\
\qquad \mathrm{N}=30\end{array}$} & \multicolumn{2}{|c|}{$\begin{array}{c}\text { Acupuncture } \\
\text { group } \\
\mathrm{N}=21\end{array}$} & \multicolumn{2}{|c|}{$\begin{array}{l}\text { Laser } \\
\text { group } \\
\mathrm{N}=25\end{array}$} & \multirow[t]{2}{*}{$\mathrm{F}$} & \multirow[t]{2}{*}{$P$} \\
\hline & Mean & ${ }_{ \pm} \mathrm{SD}$ & Mean & ${ }_{ \pm} \mathrm{SD}$ & Mean & $+\mathrm{SD}$ & & \\
\hline Weight (Kg) & 80.94 & 15.99 & 94.70 & 19.68 & 89.34 & 18.04 & 3.75 & 0.028 \\
\hline $\mathrm{BMI}\left(\mathrm{Kg} / \mathrm{m}^{2}\right)$ & 32.54 & 6.79 & 35.77 & 5.84 & 38.54 & 9.60 & 4.10 & 0.021 \\
\hline Waist C (cm) & 93.85 & 12.80 & 101.00 & 16.16 & 99.90 & 13.50 & 1.83 & 0.167 \\
\hline Hip C (cm) & 110.92 & 10.10 & 125.00 & 14.71 & 121.30 & 19.00 & 5.72 & 0.005 \\
\hline $\begin{array}{l}\text { Waist/Hip ratio } \\
(\mathrm{cm} / \mathrm{cm})\end{array}$ & 0.84 & 0.06 & 0.80 & 0.04 & 0.83 & 0.05 & 3.86 & 0.026 \\
\hline Neck C (cm) & 37.19 & 3.20 & 37.67 & 4.29 & 40.10 & 2.10 & 5.73 & 0.005 \\
\hline $\begin{array}{l}\text { Visceral fat by } \\
\text { US at mbilicus }\end{array}$ & 4.82 & 2.03 & 4.00 & 2.18 & 6.41 & 2.37 & 7.33 & 0.001 \\
\hline
\end{tabular}

Reviewing literatures, it was found that there is little published research regarding comparison between different protocols that can be used with confidence. Lamarche et al., [13] and Di Buono et al., [14], found that energy restriction resulting in even modest weight loss suppresses endogenous cholesterol synthesis which leads to a decline in circulating lipid concentrations and increased insulin sensitivity that contributes in improving lipoprotein profile after treatment of obesity. While Wozniar et al. [15], in agree with current results; found that a combination of a laser acupuncture and low-caloric diet is characterized by higher efficiency than a low caloric- diet alone in lowering body weight, body mass index, waist/hip ratio. Chu et al. [16] reported that acupuncture has a good regulation effect on lipid metabolism and plasma cycling adenosine monophosphate (cAMP). They found that auricular acupuncture plus body acupuncture reduce triglycerides and total blood cholesterol levels in overweight and obese subjects. Zhou-hong [17] in China, also stated that acupuncture can provide good therapeutic effects for simple obesity, as after twenty sessions, the body weight, the serum total cholesterol (TC), the fasting triglyceride (TG) and low-density lipoprotein (LDL) were significantly changed. Lee et al. [18] reported that electro acupuncture lead to normalization of blood serum lipids, reduction of body mass and decrease fatty tissues content. They attributed the effect of acupuncture to its beneficial effect on hypothalamus-pituitary axis. Adipose tissue in liver produce cAMP by the membranous enzyme adenylate cyclase that acts on ATP producing cAMP and liberating pyrophosphate; cAMP is involved in the activation of phosphorylase helping glycogenolysis and on lipase enzyme helping lipolysis [16, 19]. Zhang et al. [20] was demonstrating that acupuncture therapy significantly reduces abdominal adipose tissue by reducing abdominal visceral fat content without significant changes in body weight, waist circumference, hip circumference, waist/hip ratio or abdominal subcutaneous adipose tissue. Thus, they stressed the use of acupuncture therapy to selectively target a reduction in abdominal visceral fat content; which should become more important and more popular in the future.

In contrast to results of the present study, Ghroubi et al. [3] in Tunis, also, found that acupuncture stimulation of mouth, stomach, hunger and spleen auricular points for 2 to 6 weeks resulted in weight loss in these patients varied from 2-16 pounds. There was also a significant increase in HDLC (improvement) which was greater in group received dietary measures and physical training than group received dietary measures and physical training with acupuncture.

Table 10: Comparison between blood pressure and lipid profile among the 3 groups of females after intervention using ANOVA.

\begin{tabular}{|c|c|c|c|c|c|c|c|c|}
\hline & \multicolumn{2}{|c|}{$\begin{array}{l}\text { Nutritional group } \\
\mathrm{N}=30\end{array}$} & \multicolumn{2}{|c|}{$\begin{array}{l}\text { Acupuncture } \\
\text { group } \\
\mathrm{N}=21\end{array}$} & \multicolumn{2}{|c|}{$\begin{array}{l}\text { Laser group } \\
\mathrm{N}=25\end{array}$} & \multirow[t]{2}{*}{$\mathrm{F}$} & \multirow[t]{2}{*}{$\mathrm{P}$} \\
\hline & Mean & $\pm \mathrm{SD}$ & Mean & ${ }_{ \pm} \mathrm{SD}$ & Mean & $\pm \mathrm{SD}$ & & \\
\hline $\begin{array}{l}\text { SBP } \\
\text { DBP }\end{array}$ & 115.00 & 17.1270 & 145.00 & 5.19 & $\begin{array}{r}120.00 \\
80.00\end{array}$ & 8.45 & 27.50 & 0.000 \\
\hline $\begin{array}{l}\text { DBP } \\
\text { Fasting }\end{array}$ & 81.87 & 8.1394 & 105.00 & 5.19 & 80.00 & $\begin{array}{r}0.00 \\
16.1\end{array}$ & $\begin{array}{r}87.47 \\
6.1\end{array}$ & 0.000 \\
\hline $\begin{array}{l}\text { blood sugar } \\
\text { Total }\end{array}$ & 96.47 & 30.93 & 86.00 & 12.15 & 109.20 & 16.14 & 6.15 & 0.003 \\
\hline cholesterol & 228.60 & 29.53 & 208.67 & 31.44 & 206.00 & 24.49 & 5.15 & 0.008 \\
\hline $\begin{array}{l}\text { Triglycerides } \\
\text { HDL } \\
\text { LDL }\end{array}$ & $\begin{array}{r}151.13 \\
48.40 \\
150.07\end{array}$ & $\begin{array}{l}63.55 \\
10.36 \\
35.98\end{array}$ & $\begin{array}{r}142.00 \\
58.00 \\
141.33\end{array}$ & $\begin{array}{r}27.95 \\
2.90 \\
13.76\end{array}$ & $\begin{array}{r}146.60 \\
60.60 \\
115.00\end{array}$ & $\begin{array}{l}47.49 \\
23.21 \\
18.53\end{array}$ & $\begin{array}{r}0.20 \\
5.13 \\
12.93\end{array}$ & $\begin{array}{l}0.817 \\
0.008 \\
0.000\end{array}$ \\
\hline
\end{tabular}

Soong [21], reported that waist and hip circumference, lipid metabolism and the levels of cyclic adenosine monophosphate (cAMP) can be regulated by acupuncture, as acupuncture stimulates the auricular branch of vagus nerve and raises serotonin levels, both of which have been shown to increase tone in the smooth muscles of the stomach, thus suppressing the appetite which leads to weight loss in overweight patients [22]. 
Bilateral auricular acupuncture stimulation clearly modulates feeding-related hypothalamic neuronal activity of experimental (both hypothalamic and dietary) obese rats [23] by elect pressure on auricular acupoint plus body acupuncture for 3 months was superior in reduction body weight and decrease in appetite than obese treated by diet in subjects with simple obesity [24].

Bounds et al. [25] revealed that exercise resulted in an increase in HDL-c (10.7\%) and a concomitant fall in triglyceride $(-25 \%)$ and total cholesterol (-3.5\%), which may be mediated; at least in part; by an increase in lipoprotein lipase activity [26]. These results came against current ones.

In conclusion, the three management's protocols had highly significant effect on visceral obesity but nutritional intervention alone could be used to reduce weight if the lipid profile within normal range, but if it is impaired, acupuncture should be used beside. To strength the reduction in body anthropometry, laser acupuncture intervention was recommended beside the nutritional intervention.

\section{Statement of authorship}

Nayera E. Hassan: Conception and design of the study, share in drafting the article and final approval of the version to be submitted. She is the PI of the project from which this data was derived. Sahar A. El-Masry: Analysis and interpretation of the data, share in drafting the article and final approval of the version to be submitted. She is the Co-PI of the project from which this data was derived. Salwa M Elshebini and Nihad H Ahmed: Responsible for dietary intervention with physical exercise management protocol. Muhamed Al-Tohamy: Share in data collection and drafting the article. Enas Abdel Rasheed and Gamila SM El-Saeed: Responsible for the laboratory investigations. Nagwa $H M$ and Emad NZ: Responsible about acupuncture and laser acupuncture management protocols. Mohamed S El Hussieny: Responsible of the ultrasound for estimation of visceral fat and subcutaneous abdominal fat. All authors share in data collection and final approval of the version to be submitted.

\section{Acknowledgments}

We would like to acknowledge our institute "National Research Centre', Egypt", without its fund this study could not be done. We would also like to acknowledge everybody participated in this study, the employers of our institute who were the participants of this study, the technicians who helped in the laboratory analysis and the doctors who participated in collection of the data'. Without their help, this study couldn't have been completed.

\section{References}

1. World Health Organization. "Obesity and Overweight Fact Sheet, $2011.2 \quad$ Available http://www.who.int/mediacentre/factsheets/fs311/en/index.html AccessedSeptember2011

2. Egypt Demographic and Health Survey. Nutritional status. Chapter 14, 2008:pp.183-195.
3. Ghroubi S, Elleuch H, Chikh T, Kaffel N, Abid M, Elleuch MH. Physical training combined with dietary measures in the treatment of adult obesity. A comparison of two protocols. Annals of Physical and Rehabilitation Medicine. 2009; 52 . 394-413.

4. Hong S. Relation between Treatment Course and Therapeutic Effects of Acupuncture for Female Obesity of Different Types. Journal of Traditional Chinese Medicine. 2008; 28(4): 258-261.

5. Jelcić J, Korsić M. Obesity as a medical and public health problem. Lijec Vjesn. 2009; 131(9-10):279-85.

6. Beechy L, Galpern J, Petrone A, Das SK. Assessment tools in obesity - Psychological measures, diet, activity, and body composition. Physiology \& Behavior. 2012; 107:154-171.

7. Seagle HM, Wyatt HR, Hill JO. Obesity: overview of treatments and interventions. Nutrition in the Prevention and Treatment of Disease, Third Edition, 2013:pp 445-464.

8. Hiernaux J, Tanner JM. Growth and physical studies. In: Human Biology: A guide to field methods. Weiner JS, Lourie SA, editors. Oxford. U.K: IBP. London: Blackwell Scientific Publications, 1969

9. Friedewald WT, Levy RI, Fredrickson DS. Estimation of the concentration of low-density lipoprotein cholesterol in plasma, without use of the preparative ultracentrifuge. Clin Chem. 1972;18(6):499-502.

10. WHO 2008: who Standard Acupuncture Point Location in the Western Pacific Region, Jun 25.2008 -249 pages.

11. FAD Laser Information 2009: Compliance Guide For Laser Products, US Department of Health and Human Services Public Health Service FAD Center for Devices and Radiological Health HHS publication FDA, 2009: 86-8260.

12. National Heart, Lung, and Blood Institute, Obesity Education Initiative Expert Panel, Clinical guidelines on the identification, evaluation, and treatment of overweight and obesity in adults: the evidence report, Obes.Res. 1998;6(Suppl.2): 51S_209S.

13. Lamarche $B$, Després JP, Pouliot MC, Moorjani $S$, Lupien $P J$, Thériault G, Tremblay A, Nadeau A, Bouchard C. Is body fat loss a determinant factor in the improvement of carbohydrate and lipid metabolism following aerobic exercise training in obese women? Metabolism. 1992;41(11):1249-56.

14. Di Buono M, Hannah JS, Katzel LI, Jones PJ. Weight loss due to energy restriction suppresses cholesterol biosynthesis in overweight, mildly hypercholesterolemic men. J Nutr. 1999;129(8):1545-8

15. Wozniar, P., G. Stachowiak, A K. Pieta-Dolinska and J. Oszkowski. Laser acupuncture and low-calorie diet during visceral obesity therapy after menopause. Acta Obtst. Gynecol. Scand. 2003; (1): 69-73.

16. Chu, N.F., M.J. Stampfer, D. Splegelman, N. Rifai, G.S. Hotamisligil and E.B. Rimm. Dietary and lifestyle factors in relation to plasma leptin concentrations among normal weight and overweight men. Int. J. Obes. Relat. Metab. Disord. 2001;5(1): 106-14.

17. Zhou-hong WU. Effects of the Multiple Needling with Shallow Insertion for Simple Obesity: A Clinical Observation on Lipid Metabolism and on the Chest, Waist and Hip Circumferences. J. Traditional Chinese Medicine. 2009; 29: 179-181.

18. Lee, Myeong Soo, Kim Jeong Hwan, Lim Hyun-Ja and Shin Byung-Cheul. Effects of abdominal electroacupuncture on parameters related to obesity in obese women: A pilot study. Complementary Therapies in Clinical Practice. 2009; 12: 97100.

19. Sun, F. The antiobesity effect of acupuncture and its influence on water and salt metabolism. Zhen. Ci. Yan. Jiu. 1996;21(2): 19-24.

20. Zhang H, Peng Y, Liu Z, Li S, Lv Z, Tian L, Zhu J, Zhao 
$X$, Chen M. Effects of acupuncture therapy on abdominal fat and hepatic fat content in obese children: a magnetic resonance imaging and proton magnetic resonance spectroscopy study. J Altern Complement Med. 2011 May;17(5):413-20.doi: 10.1089/acm.2010.0322

21. Soong, Y. The treatment of exogenous obesity employing auricular acupuncture. Am. J. Chin. Med. 1975; 3(3): 285-7.

22. Richards, D. and Marley J. Stimulation of auricular acupuncture points in weight loss. Aust. Fam. Physician. 1998; 27 (Suppl.) 2: S73-S7.

23. Shiraishi, T., M. Onoe, T. Kojima, Y. Sameshima and Kageyama. Effect of auricular stimulation on feeding-related hypothalamus neuronal activity in normal and obese rats. Brain Res. Bull. 1995; 6 (2): 141-8.

24. Shiriaishi, T., M. Onoe, T.A. Kojima, T. Kageyama, Sawatsugawa, K. Saku, H. Yoskhimatsu and Sakata. Effects of bilateral auricular acupuncture stimulation on body weight in healthy volunteers and mildly obese patients. Exp. Biol. Med., (Maywood). 2003;28(10): 1210-7.

25. Bounds RG, Grandjean PW, O'Brien BC. Inman C, Crouse SF. Diet and short term plasma lipoprotein lipid changes after exercise in trained men. Int $\mathrm{J}$ Sport Nutur Exerc Metab. 2000;10 (2): 114-27.

26. Grandjean PW, Crouse SF, Rohack JJ. Influence of cholesterol status on blood lipid and lipoprotein enzyme responses to aerobic exercise. J Appl Physiol. 2000;89 (2): $472-80$. 